\title{
The Inhibitive Effect of Some Amino Acids on the Corrosion Behaviour of 316L Stainless Steel in Sulfuric Acid Solution
}

\author{
N.A. Abdel Ghanyl \\ Physical Chemistry Department, National Research Center, Dokki, Egypt
}

A. E. El-Shenawy \& W.A.M.Hussien

Chemistry Department, Faculty of Science, Al-Azhar University, Cairo, Egypt

Received: May 5, 2011

Accepted: May 31, 2011

doi:10.5539/mas.v5n4p19

\begin{abstract}
The inhibition effect of four amino acids on the corrosion of $316 \mathrm{~L}$ stainless steel in $1.0 \mathrm{M} \mathrm{H}_{2} \mathrm{SO}_{4}$ has been studied by open-circuit potential and potentiodynamic polarization measurements. Corrosion data such as corrosion rate, corrosion potential $\left(\mathrm{E}_{\text {Corr. }}\right)$ and corrosion current $\left(\mathrm{I}_{\text {Corr. }}\right)$ were determined by extrapolation of the cathodic and anodic Tafel region. Glycine, Leucine and Valine inhibit the corrosion process, but Arginine accelerate the corrosion phenomenon. Glycine has the highest inhibition efficiency, its efficiency increases with increasing the concentration to attain $84.2 \%$ at $0.1 \mathrm{M}$. Different behaviours were observed, in case of Arginine, corrosion rate increase by increasing concentration. These results show that the presence of Arginine at high concentration turns the surface of $316 \mathrm{~L}$ stainless steel electrochemically active, probably dissolving the passivation layer and promoting the stainless steel anodic dissolution. Results obtained from potentiodymaic and open-circuit potential measurements are in good agreement.
\end{abstract}

Keywords: Amino acids, 316L stainless steel, Sulfuric acid

\section{Introduction}

Austenitic stainless steel are widely used in various chemical industries, due to their superior corrosion protection through a passive oxide layer forms on their surfaces, when exposing to an aqueous environments. Although the main characteristic of these materials is high resistance to corrosion, but when coming in contact with chloride ions, they undergo of localized corrosion and lose their passivity properties (A. Pardon, M.C. Merino, A.E. Coy, F. Viejo, R. Arrabal, E. Matykina. 2008)( I. Gurappa. 2002)( T.L. Sudesh, L. Wijesinghe, D.J. Blackwood, 2006)(C.V. Vidal, A.I. Munoz. 1954)(P. Fauvet, F. Balbaud, R. Robin, Q.T.Tran, A. Mugnier, D. Espinoux, 2008). Sulphuric acid is commonly used in removing the undesirable scale and rust in metal working, such as cleaning of boilers and heat exchangers(Muzaffer zcan, Ramazan Solmaz, Gülfeza Kardas, 2008)(F. Bentiss, M. Bouanis, B. Mernari, M. Traisnel, H. Vezin, M. Lagrenée, 2007)(Nabel A. Negm, Mohamed F. Zaki, 2008). Since acids are an aggressive medium for oil and gas well equipment, the effective way to reduce their corrosion attack on tubing and casing materials, is to inject a suitable corrosion inhibitor which could be added to the acid solution during the acidifying process (C. Kustu, K.C. Emregul, O. Atakol. 2007)( M.A. Migahed, I.F. Nassar. 2008)( M.A. Quraishi, D. Jamal. 2000)( M.A. Quraishi, D. Jamal, 2001). For austenitic stainless steel, the electrochemical tests revealed generally low resistance to pitting for hydrochloric acid concentrations of $0.1,0.5$, and $0.9 \mathrm{M}$ (J. Alhajji. 1997). Comparative study of surface properties of austenitic stainless steels in sulfuric and hydrochloric acid solutions (K. Varga, P. Baradlai, W.O. Barnard, G. Myburg, P. Halmos and J.H. Potgieter. 1997), from the experimental results, it is obvious that the surface excess values of bisulfate/sulfate ions on both stainless steels (316L and 304L) are much higher (up to $1.5 \times 10^{-9} \mathrm{~mol} \mathrm{~cm}^{-2}$ ) and their interaction with the passive oxide layer is substantially stronger than those of chloride ions. The surface concentration of $\mathrm{Cl}^{-}$of less than $2 \times 10^{-10} \mathrm{~mol} \mathrm{~cm}^{-2}$ provides evidence that only a very limited part of the real surface area of the steel samples (less than $5 \%$ ) is occupied by $\mathrm{Cl}^{-}$ions, ie, pitting corrosion sites are probably formed. The corrosion behavior of stainless steel samples (316 $\mathrm{L}$ and $304 \mathrm{~L}$ ) in $\mathrm{HCl}$ and $\mathrm{H}_{2} \mathrm{SO}_{4}$ solution has been studied using potentiodynamic, cyclic voltammogram, EDX and SEM techniques(D.J. Shaw, 1966).

Amino acids are nontoxic, relatively cheap and easy to produce with purities greater than $99 \%$ (R.C. Bohinski. 1973). The use of chemical inhibitors is the most practical method for the protection against corrosion in acidic solutions (M. Mihit S. El Issami, M. Bouklah, L. Bazzi, B. Hammout, E. Ait Addi, R. Salghi, S. Kertit. 2006)(M. Mihit, R. Salghi, S. El-Issami, L. Bazzi, B. Hammouti, I. Ait Addi, S. Kertit, Pigm. 2006)(A. Dafali, B. Hammouti, R. Mokhlisse, S. Kertit, 2003)(S. Kertit, R. Salghi, L. Bazzi, B. Hammouti, A. Bouchtart, Ann. 2000). Several studies have been performed on the use of organic compounds as inhibitors for the corrosion of metals in aggressive acidic media. Most of the natural amino acids are the alpha amino acids which contain carboxyl and amino groups bonded to the same carbon atom. It was shown that the inhibition action of some organic compounds is based on adsorption phenomenon (L. Bazzi, S. Kertit, M. Hamdani. 1995). Inhibition effect of 
hexadecyl pyridinium bromide on the corrosion behavior of some austenitic stainless steels in $\mathrm{H}_{2} \mathrm{SO}_{4}$ solutions has been studied (M.M. Hamza, S.S. Abd El Rehim, A.M. Ibrahim. 2011). Electrochemical corrosion behavior and hydrogen evolution reaction of 316L stainless steel has been investigated in $0.5 \mathrm{M}$ sulfuric acid solution containing four novel organic inhibitors as derivatives from one family, using potentiodynamic polarization, electrochemical impedance spectroscopy (EIS) measurements and surface examination via scanning electron microscope (SEM) techniques (Nada F. Atta, A.M. Fekry, Hamdi M.Hassaneen, 2011). Fourier-transform infrared spectroscopic analysis and semiempirical molecular orbital calculations were carried out to analyse the ionization states and configuration of amino acid adsorption on a stainless steel surface.

The aim of this research, may throw some light on the corrosion inhibition of some aliphatic amino acids on $316 \mathrm{~L}$ stainless steel in sulfuric acid solution.

\section{Experimental}

Circular electrode with working surface area of $1.76 \mathrm{~cm}^{2}$ were used. The chemical composition given in Table 1 . Electrode was ground with emery paper and polished with diamond paste $(1 \mu \mathrm{m})$, finally the sample was cleaned by acetone, washed by distilled water, and quickly inserted in the cell. All experiments were carried out under total immersion in $100 \mathrm{ml}$ of test solutions. Saturated calomel electrode (SCE) and platinium electrode were used as reference and auxiliary electrodes, respectively. The stirred electrolyte used, as a corrosive media was $1.0 \mathrm{M}$ $\mathrm{H}_{2} \mathrm{SO}_{4}$ aerated solution, prepared from analytical reagent grade concentrated acid using distilled water at $25 \pm$ $2^{\circ} \mathrm{C}$. The open-circuit potential of the metal immersed in the test solutions were monitored using the electronic multimeter (Type E scord-EDM-2116). The electrode was allowed to stabilize in the electrolyte until the potential change was $<0.1 \mathrm{mV} / \mathrm{min}$. This potential was taken as the steady state potential $\left(\mathrm{E}_{\mathrm{s.s} .}\right)$. Potentiodynamic polarization studies were carried out in the potential range $\pm 250 \mathrm{mV}$ vs corrosion potential $\left(\mathrm{E}_{\text {Corr. }}\right)$ at a scan rate of $0.5 \mathrm{mV} / \mathrm{s}$. The studies were performed with model $352 / 252$ corrosion measurement system, which consists of EG \& G potentiostat/galvanostat model $273 \mathrm{~A}$.

The amino acids used in those investigations are Glycine, Leucine, Valine and Arginine as example for aliphatic amino acids at different concentrations range from $0.005-0.1 \mathrm{M}$ in $1.0 \mathrm{M} \mathrm{H}_{2} \mathrm{SO}_{4}$ solution.

\section{Results and discussion}

\subsection{Open-circuit potential measurements}

The open-circuit potentials of stainless steel electrode were traced about $90 \mathrm{~min}$. from electrode immersion in solutions. Generally the steady state was reached within $60 \mathrm{~min}$. from electrode immersion in the test solution. Steady state potential is shifted either in the negative or positive direction in the presence of the amino acids. The direction of the potential shift depends on the type and concentration of the amino acids. Fig.1, represents the variation of the open-circuit potentials with time of $316 \mathrm{~L}$ stainless steel electrode in $1.0 \mathrm{M} \mathrm{H}_{2} \mathrm{SO}_{4}$ solution in absence and in presence of different concentrations of amino acids. The values of the steady state potentials $\left(\mathrm{E}_{\mathrm{s.s} .}\right)$ and the immersion potential $\left(\mathrm{E}_{\mathrm{im}}\right.$.) in the presence of different concentrations of different amino acids are given in Table 3.

The variation of the steady state potentials $\left(\mathrm{E}_{\text {s.s. }}\right)$ with the logarithmic of the molar concentrations of test solutions, is presented by the curves in Fig.2. According to the change of the steady state potentials with $\log \mathrm{C}$, the amino acids studied may be classified into two classes. The first one comprised (Arginine, Leucine and Valine), while the second belong Glycine. The results show that the open-circuit potentials and the steady state potentials depend on the type and concentration of the amino acids Table (3).

In class one which include Leucine, Valine and Arginine, steady state potential values were shift towards more negative values with increasing the amino acid concentration. This behaviour can be attributed to the influence of the inhibitor on the anodic process, especially at high inhibitor concentrations (K.M. Ismail. 2003). These results show that the presence of amino acids (Leucine, Valine and Arginine) at high concentrations turns the surface of 316L stainless steel electrochemically active, probably dissolving the passivation layer and promoting the stainless steel anodic dissolution (A.B. Silva, S.M.L. Agostinho, O.E. Barcia, G.G.O. Cordeiro, E.D' Elia, 2006).

Inspection of the potential-time curves in case of Glycine Fig.1 (a), steady state potential shift towards more noble values. This can be attributed to the formation of a protective layer of Glycine on the electrode surface (E.E. Orguzie, S.G. Wang, Y.Li, F.H.Wang. 2008).

\subsection{Potentiodynamic polarization measurements}

Effect of some amino acids on 316L stainless steel in aqueous $1.0 \mathrm{M} \mathrm{H}_{2} \mathrm{SO}_{4}$.

Organic corrosion inhibitors function by chemisorption of their molecules on metallic substrate, complexing of the molecules with metal ions, that remain in solid lattices, neutralizing the corrodent and/or absorbing the corrodent. Many organic compounds containing polar group and $\pi$ electrons are good corrosion inhibitor for steels (A.M. Badawi, S.T. Keera and M.A. Hussein, 2001)(T. Giordano, 1987). In acidic solutions, these compounds exist as protonated species. This protonated species may adsorb on the cathodic sites of the stainless steel surface according to Langmuir isotherm, and decrease the evolution of hydrogen. And also are able to 
adsorb on anodic sites through nitrogen atom. The adsorption of these compounds on anodic sites may decrease anodic dissolution of the stainless steel electrodes. The inhibition of organic compounds is strongly depended on the structure and chemical properties of the layer formed on the metal surface under particular experimental conditions(S.A.M. Refaey, F. Taha and A. M. Abd El-Malak. 2004). Such behaviour may also be considered in line with an earlier suggestion, that a molecule may first physically adsorb, and then slowly react with the metal surface to form a chemisorbed layer (D.J. Shaw, 1966).

a- Effect of Glycine

Fig. 3 shows the polarization curves for the effect of different concentrations of Glycine on the potentiodynamic behaviour of $316 \mathrm{~L}$ stainless steel in $1.0 \mathrm{M} \mathrm{H}_{2} \mathrm{SO}_{4}$ solution. Generally with increasing inhibitor concentration the corrosion current density $\left(\mathrm{I}_{\text {Corr. }}\right)$ and corrosion rate decrease. It indicates that, according to increasing, inhibitor concentration its adsorption to metal surface increases and protects the metal from corrosion. The inhibition effect of glycine towards the corrosion of low alloy steel ASTM A213 grade T22 boiler steel was studied in aerated stagnant $0.5 \mathrm{M} \mathrm{HCl}$ solutions in the temperature range $20-60{ }^{\circ} \mathrm{C}$, the results show that glycine is good "green", mixed-type inhibitor with cathodic predominance(Mohammed A. Amin, Sayed S. Abd El Rehim, Hesham T.M. Abdel-Fatah, 2009).

The corrosion rate can be calculated from the following equation:

Corrosion rate $(\mathrm{mpy})=\frac{0.13 \mathrm{I}_{\text {corr. }}(\mathrm{E} . \mathrm{W})}{\text { A.d. }}$

Where:

E.W. = equivalent weight (in g.eq.)

$\mathrm{A}=$ area $\left(\right.$ in $\left.\mathrm{cm}^{2}\right)$

$\mathrm{d}=\operatorname{density}\left(\mathrm{g} . / \mathrm{cm}^{3}\right)$

$0.13=$ metric and time conversion factor.

Also the inhibitor efficiencies calculated from the polarization method using the equation,

$\mathrm{IE}=\frac{\left(\mathrm{I}_{\text {Corr }}\right)_{\text {uninh }}-\left(\mathrm{I}_{\text {Corr }}\right)_{\text {inh. }}}{\left(\mathrm{I}_{\text {Corr }}\right)_{\text {uninh }}} \times 100$

Where $\left(\mathrm{I}_{\text {Corr. }}\right)_{\text {uninh. }}$ and $\left(\mathrm{I}_{\text {Corr. }}\right)_{\text {inh. }}$ are the corrosion current densities obtained by extrapolation of the cathodic and anodic Tafel lines, in uninhibited and inhibited solutions, respectively. All parameters were measured and reported in Table 4.

According to the results, $\mathrm{E}_{\mathrm{Corr}}$ shifts to more negative (less positive) values and that indicates, in this case, the inhibitor have been adsorbed to cathodic areas and acts as cathodic inhibitor (H. Ashassi-Sorkhabi, M.R. Majidi, K. Seyyedi, 2004).

The amino acid presents in its protonated form in acidic solution, therefore, the amino acid in this form can be attracted to the cathodic sites on the metal surface.

It is clear from the potentiodynamic experiments that the presence of Glycine, decrease the corrosion rate, i.e. the values of $\mathrm{I}_{\text {Corr. }}$ decreases. Furthermore, the addition of Glycine shifts, the potential of metal in the negative direction due to the decrease in the rate of the cathodic reaction. Particularly, the cathodic reaction is inhibited to larger extent than the anodic reaction (K.M. Ismail. 2007).

The inhibition efficiencies increase as the inhibitor concentration increases and reach maximum values of $84.2 \%$ (at 0.1M Glycine)( W.A. Badawy, K.M. Ismail, A. M. Fathi. 2006).

\section{b- Effect of Leucine}

Leucine is a passivating inhibitor, as it is found to decrease the passivation current (Puja Singh, Kalpana Bhrara Gurmeet Singh. 2008). The various corrosion parameters, like $\mathrm{E}_{\text {Corr. }}, \mathrm{I}_{\text {Corr. }}$, corrosion rate and inhibition efficiency in presence of different concentrations of Leucine calculated and tabulated in Table 5. The recorded results in Fig. 4 indicated that, the corrosion current $\left(\mathrm{I}_{\text {Corr. }}\right)$ are lower in the presence of Leucine as compared to the acid free solution. From the results, found that $\mathrm{E}_{\mathrm{Corr}}$ shift towards more negative values by increase the concentration of Leucine, indicate that, Leucine act as cathodic inhibitor. The corrosion inhibition process is based on the adsorption of the amino acid molecules on the active sites and/or deposition of the corrosion products on the metal surface(W.A. Badawy, K.M. Isamil, A.M., Fathi, 2005)( G. Bereket, A. Yurt, 2001). In the present case owing to high acidity of the medium, Leucine is present in the protonated form as(J.P. Greenstein, M. Winitz, 1961):<smiles>CC(C)CC([NH3+])C(=O)O</smiles> 
Therefore, it is clear that in the strong acid medium under consideration both the carboxylic and the amino groups of the additive are expected to be fully protonated. Both the functional groups get adsorbed on the cathodic sites of the corroding metal. The following figure represents the schematic presentation of the mode of adsorption of amino acids over the metal surface (A.S. Fouda, M.M.E. Semongy. 1982).

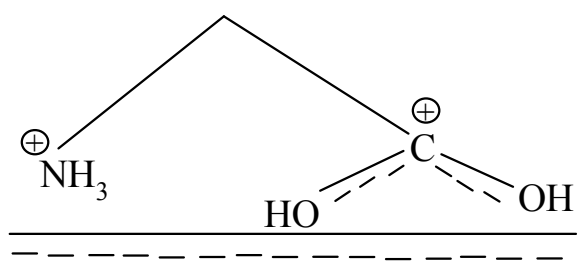

\section{C-Effect of Valine}

The anodic and cathodic curves observed in Fig. 5, in absence and presence of Valine and the results obtained tabulated in Table 6 , show that the corrosion rate of 316L stainless steel decrease in case of presence of Valine than in case absence of Valine. However, the addition of Valine inhibits the corrosion phenomenon.

In the case of Valine, nitrogen atom in aliphatic chain increases the interaction of molecule with metal surface (J.P. Greenstein, M. Winitz, 1961). Inspection of the results in Table 6, $\mathrm{E}_{\text {Corr. }}$ shifts to more positive values by increasing the concentration of Valine, in this case, Valine acts as anodic inhibitor (W.A. Badawy, K.M. Ismail, A. M. Fathi. 2006). Further increase in the inhibitor concentration shows a slight decrease in the inhibition efficiencies. This phenomenon is consistent with results obtained for other inhibitors and is attributed to the dissolution of the adsorbed film (P. Gupta, R.S. Chaudhary, T.K.G. Nam bood hiri, B.Prakash, Br. Corros. J. 1982). The corrosion inhibit behaviour of Valine in acidic solution may be due to the formation of Fe-Valine complex, this complex can form stable passive layer on the stainless steel surface, leads to the decreasing of corrosion rate(E.E. Orguzie, S.G. Wang, Y.Li, F.H.Wang. 2008). From the results, found that, the inhibition efficiency depends on the concentration of the inhibitor.

d-Effect of Arginine

Arginine accelerates the corrosion rate and it relate to complexing effect of Arginine. Glycine, Leucine and Valine as example for aliphatic amino acids, while Arginine as basic amino acids (W.A. Badawy, K.M. Ismail, A. M. Fathi. 2006).

In case of Arginine solution, as the formation of the complexes between metal and amino acid (Arginine), since Arginine acting as bidentate ligand, this behvaiour, results in change in the corrosion potential of 316L stainless steel in the active direction, followed by increase in the corrosion rate. All parameters were observed and are given in Table 7. Inspection of this results, observed that, corrosion potential of $316 \mathrm{~L}$ stainless steel shifts to more negative values, while $\mathrm{I}_{\text {Corr. }}$ and corrosion rate increase by increasing the concentration of Arginine. These results suggest that the presence of Arginine, promoted an more active surface. Fig. 6, shows polarization curves for the effect of different concentrations of Arginine in $1.0 \mathrm{M} \mathrm{H}_{2} \mathrm{SO}_{4}$. From the Fig. 6, observed that, all curves exhibit active dissolution without any distinctive transition to passivation within the studied potential range(D.J. Shaw. 1966). The presence of the active region suggests, a dissolution of the passivation layer, probably due to the Arginine complexes formed with the metallic ions present in this film. Consequently, the knowledge of their corrosion activity is highly essential. Further, the effect of length of C-atom chain(O. Olivares - Xometl, N.V. Likhanova, M.A. Dominguez-Aguilar, E. Arce, H. Dorantes, P. 2008), along aliphatic chain promoted not only higher corrosion efficiency, but also a higher toxicity. Arginine has a radical $\mathrm{R}$ which contains nitrogen, effectiveness remains low because the existence of a tautomeric and a steric hindrance at nitrogen atoms(M.Zerfaoui, H.Oudda, B. Hammouti, S.Kertit, M. Benkaddour. 2004). These results in Table 7, were in agreement with some authors, have shown that some amino acids have been demonstrated to be able to enhance the corrosion process(W. Sand. 1997)( H.H.P. Fang, L.C. Xu, K.Y. Chan. 2002).

\section{Conclusion}

The present work involves open-circuit potential and potentiodynamic polarization techniques for studying the effect of different amino acids on the corrosion of $316 \mathrm{~L}$ stainless steel in $1.0 \mathrm{M} \mathrm{H}_{2} \mathrm{SO}_{4}$ solution.

From the obtained results, we may conclude:

1) In general, amino acids with longer hydrocarbon chain showed greater inhibition, addition of amino groups or groups which increase electron density on alph amino group also increased the inhibition efficiency.

2) It is evident from the obtained values of $E_{\text {Corr. }}, I_{\text {Corr. }}$ and inhibition efficiencies that, the decrease in the corrosion rate associated with positive or negative shift in the corrosion potential.

3) Glycine, Valine and Leucine act as corrosion inhibitors but Arginine act as corrosion accelerator.

4) The inhibition efficiency follows the following order:

Glycine $(84.2 \%)>$ Valine (38.2\%) > Leucine (33.5\%). So Glycine..is the best inhibitor 


\section{Acknowledgement}

The author wishes to express her thanks and sincere gratitude to Prof. Dr. Rabab M. Abou-Shahba.

\section{References}

A. Dafali, B. Hammouti, R. Mokhlisse, S. Kertit. (2003). Corros. Sci. 45(2003) 1619.

A. Pardon, M.C. Merino, A.E. Coy, F. Viejo, R. Arrabal, E. Matykina. (2008). Corros. Sci. 50(2008) 1796.

A.B. Silva, S.M.L. Agostinho, O.E. Barcia, G.G.O. Cordeiro, E.D' Elia, (2006). Corros. Sci. 48 (2006) 3668.

A.M. Badawi, S.T. Keera and M.A. Hussein. (2001). Egyptian Petroleum Journal 10(2) (2001) 25.

A.S. Fouda, M.M.E. Semongy. (1982). J. Ind. Chem. Soc. Vol. LIX (1982) 89.

C. Kustu, K.C. Emregul, O. Atakol. (2007). Schiff bases of increasing complexity as steel corrosion inhibitors in $2 \mathrm{M} \mathrm{HCl}$, Corros. Sci. 49(2007) 2800.

C.V. Vidal, A.I. Munoz. (1954). Corros. Sci. 50(2008) 1954.

D.J. Shaw. (1966). Introduction to colloid and surface chemistry, Butt crworths, London, (1966).

E.E. Orguzie, S.G. Wang, Y.Li, F.H.Wang. (2008). J. Solid State Electrochem 12 (2008) 721.

F. Bentiss, M. Bouanis, B. Mernari, M. Traisnel, H. Vezin, M. Lagrenée. (2007). Understanding the adsorption of $4 \mathrm{H}$ - 1,2,4-triazole derivatives on mild steel surface in molar hydrochloric acid, Appl. Surf. Sci. 253 (2007) 3696.

G. Bereket, A. Yurt. (2001). Corros. Sci. 43 (2001) 1179.A. Dafali, B. Hammouti, R. Mokhlisse, S. Kertit, Corros. Sci. 45(2003) 1619.

H. Ashassi-Sorkhabi, M.R. Majidi, K. Seyyedi. (2004). Appl. Surf. Sci. 225 (2004) 176.

H.H.P. Fang, L.C. Xu, K.Y. Chan. (2002). Water Research 36(2002) 4709.

I. Gurappa. (2002). Surf. Coat.Technol.161(2002) 70.

J. Alhajji. (1997). British Corrosion Journal 32(4) (1997) 291.

J.P. Greenstein, M. Winitz. (1961). Chemistry of Amino Acids, Vol. 1, John Wiley. New York,. (1961) 518.

K. Varga, P. Baradlai, W.O. Barnard, G. Myburg, P. Halmos and J.H. Potgieter. (1997). Electrochmica Acta 42(1) (1997) 25.

K.M. Ismail. (2007). Electrochimica Acta 52 (2007) 7811.

L. Bazzi, S. Kertit, M. Hamdani. (1995). Corros. Sci. 51(11) (1995) 811.

M. Mihit S. El Issami, M. Bouklah, L. Bazzi, B. Hammout, E. Ait Addi, R. Salghi, S. Kertit. (2006). Appl. Surf. Sci. 252 (2006) 2389.

M. Mihit, R. Salghi, S. El-Issami, L. Bazzi, B. Hammouti, I. Ait Addi, S. Kertit, Pigm. (2006). Resin Technol. 35 (2006) 151.

M.A. Migahed, I.F. Nassar. (2008). Corrosion inhibition of tubing steel during acidization of oil and gas wells, Electrochmica Acta 53 (2008) 2877.

M.A. Quraishi, D. Jamal. (2000). Technical note: CAHMT-a new and eco-friendly acidizing corrosion inhibitor , Corrosion 56(2000) 983.

M.A. Quraishi, D. Jamal. (2001). Corrosion inhibition by fatty acid oxadiazoles for oil well steel (N-80) and mild steel, Materials Chemistry and Physics 71(2001) 202.

M.M. Hamza, S.S. Abd El Rehim, A.M. Ibrahim. (2011). Arabian Journal of Chemistry (2011)

M.Zerfaoui, H.Oudda, B. Hammouti, S.Kertit, M. Benkaddour. (2004). Prog. Org. Coat, 51(2004) 134.

Mohammed A. Amin, Sayed S. Abd El Rehim, Hesham T.M. Abdel-Fatah. (2009). Corros. Sci. 51(2009) 882.

Muzaffer zcan, Ramazan Solmaz, Gülfeza Kardas. (2008). Adsorption properties of barbiturates as green corrosion inhibitors on mild steel in phospheric acid, Colloids and Surfaces A: Physicochem. Eng. Aspects 325(2008) 57.

Nabel A. Negm, Mohamed F. Zaki. (2008). Corrosion inhibition efficiency of nonionic Schiff base amphiphiles of $p$-aminobenzoic acid for aluminum in $4 \mathrm{~N} \mathrm{HCl}$, Colloids and Surfaces A: Physicochem. Eng. Aspects 322(2008) 97.

Nada F. Atta, A.M. Fekry, Hamdi M.Hassaneen. (2011). International Journal of HYDROGEN ENERGY 36(2011) 6462 .

O. Olivares - Xometl, N.V. Likhanova, M.A. Dominguez-Aguilar, E. Arce, H. Dorantes, P. (2008). Arellanes Lozada, Materials Chemistry and Physics 110 (2008) 344.

P. Fauvet, F. Balbaud, R. Robin, Q.T.Tran, A. Mugnier, D. Espinoux. (2008). J. Nucl. Mater. $375(2008) 52$.

P. Gupta, R.S. Chaudhary, T.K.G. Nam bood hiri, B.Prakash. (1982). Br. Corros. J. 17 (1982) 136. 
Puja Singh, Kalpana Bhrara Gurmeet Singh. (2008). Appl. Surf. Sci. 254 (2008) 5927.

R.C. Bohinski. (1973). Modern Concepts in Biochemistry, Allyn and Bacon, Inc., Boston, Massachusetts, (1973) 60.

S. Kertit, R. Salghi, L. Bazzi, B. Hammouti, A. Bouchtart, Ann. Chim. (2000). Sci. Mat. 25(2000) 187.

S.A.M. Refaey, F. Taha and A. M. Abd El-Malak. (2004). Appl. Surf. Sci. 236 (2004) 175.

T. Giordano. (1987). Chemical Industries, 28, Corrosion Mechanism, Florian M.M.D., Ed., Marcel Dekker, UK (1987).

T.L. Sudesh, L. Wijesinghe, D.J. Blackwood. (2006). Appl. Surf. Sci. 253 (2006) 1006.

W. Sand. (1997). International Biodeterioration \& Biodegradation 40 (1997) 183.

W.A. Badawy, K.M. Isamil, A.M., Fathi, J. (2005). Applied Electrochm. 35 (2005) 879.

W.A. Badawy, K.M. Ismail, A. M. Fathi. (2006). Electrochmica Acta 51 (2006) 4182.

Table 1. Chemical composition of $316 \mathrm{~L}$ stainless steel electrode.

\begin{tabular}{|c|c|c|c|c|c||}
\hline \multicolumn{6}{|c||}{ Amount of elements (\%) } \\
\hline $\mathrm{Si}$ & $\mathrm{Cr}$ & $\mathrm{Ni}$ & $\mathrm{Mn}$ & $\mathrm{Mo}$ & $\mathrm{Fe}$ \\
\hline 0.56 & 17.28 & 10.57 & 1.14 & 2.62 & 67.83 \\
\hline
\end{tabular}

The structure of the amino acids given in Table 2 .

Table 2. Structure and molecular weight of the amino acids under study

\begin{tabular}{|c|c|c|}
\hline Name & Molecular formula & Structure \\
\hline Glycine & $\mathrm{C}_{2} \mathrm{H}_{5} \mathrm{NO}_{2}$ & $\underset{\mid}{\mathrm{NH}_{2}} \mathrm{CH}_{2}-\mathrm{COOH}$ \\
\hline Leucine & $\mathrm{C}_{6} \mathrm{H}_{13} \mathrm{NO}_{2}$ & 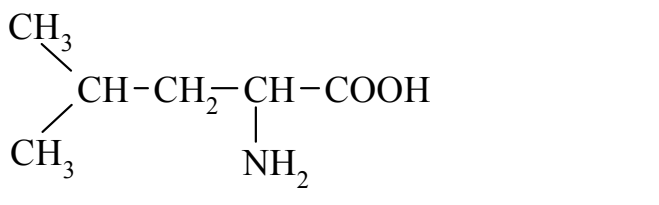 \\
\hline Valine & $\mathrm{C}_{5} \mathrm{H}_{11} \mathrm{NO}_{2}$ & $\overbrace{\mathrm{CH}_{3}}^{\mathrm{CH}}-\left.\right|_{\mathrm{NH}_{2}} ^{\mathrm{CH}-\mathrm{COOH}}$ \\
\hline Arginine & $\mathrm{C}_{6} \mathrm{H}_{14} \mathrm{~N}_{4} \mathrm{O}_{2}$ & 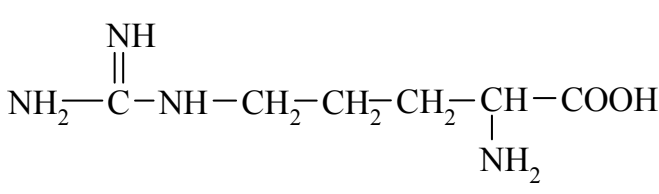 \\
\hline
\end{tabular}


Table 3. Values of $\mathrm{E}_{\text {im. }}$ and $\mathrm{E}_{\text {s.s. }}$ for $316 \mathrm{~L}$ stainless steel in 1.0.M H $\mathrm{H}_{2} \mathrm{SO}_{4}$ in absence and in presence of different amino acids.

\begin{tabular}{|c|c|c|c|}
\hline Amino acids & $\begin{array}{c}\text { Concentration } \\
\mathrm{M}\end{array}$ & $\mathrm{E}_{\text {im. }}(\mathbf{m V})$ & $\bar{E}_{\text {s.s. }}(\mathbf{m V})$ \\
\hline Blank & - & -195 & -140 \\
\hline Glycine & $\begin{array}{c}0.005 \\
0.05 \\
0.1 \\
\end{array}$ & $\begin{array}{l}-185 \\
-182 \\
-190 \\
\end{array}$ & $\begin{array}{c}-120 \\
-100 \\
-91 \\
\end{array}$ \\
\hline Leucine & $\begin{array}{c}0.005 \\
0.05 \\
0.1 \\
\end{array}$ & $\begin{array}{l}-230 \\
-180 \\
-225 \\
\end{array}$ & $\begin{array}{l}-114 \\
-137 \\
-186 \\
\end{array}$ \\
\hline \multirow{3}{*}{ Valine } & 0.005 & -230 & -160 \\
\hline & 0.05 & -198 & -185 \\
\hline & 0.1 & -235 & -190 \\
\hline \multirow{3}{*}{ Arginine } & 0.005 & -150 & -190 \\
\hline & 0.05 & -226 & -205 \\
\hline & 0.1 & -220 & -242 \\
\hline
\end{tabular}

Table 4. Corrosion parameters and inhibition efficiency for $316 \mathrm{~L}$ stainless steel in absence and presence of different concentrations of Glycine

\begin{tabular}{|l|c|l|l|l|}
\hline $\begin{array}{l}\text { Conc } \\
\mathbf{M}\end{array}$ & $\begin{array}{c}\mathbf{E}_{\text {Corr. }} \\
\mathbf{m V}\end{array}$ & $\begin{array}{l}\mathrm{I}_{\text {Corr. }} \\
\boldsymbol{\mu A} / \mathbf{c m}^{2}\end{array}$ & Corrosion rate (mpy) & $\begin{array}{l}\text { Inhibition efficiency } \\
\mathbf{I E \%}\end{array}$ \\
\hline Blank & 66.43 & 3.280 & $1485 \times 10^{-3}$ & - \\
\hline Blank + 0.005M Glycine & -57.84 & 1.879 & $850.7 \times 10^{-3}$ & 42.7 \\
\hline Blank + 0.05M Glycine & -31.86 & 0.894 & $405.2 \times 10^{-3}$ & 72.7 \\
\hline Blank + 0.1M Glycine & -4.458 & 0.516 & $233.7 \times 10^{-3}$ & 84.2 \\
\hline
\end{tabular}

Table 5. Corrosion parameters and inhibition efficiency for $316 \mathrm{~L}$ stainless steel in absence and presence of different concentrations of Leucine

\begin{tabular}{||l|l|l|l|l||}
\hline $\begin{array}{l}\text { Conc } \\
\mathbf{M}\end{array}$ & $\mathbf{E}_{\text {Corr. }} \mathbf{~} \mathbf{V V}$ & $\mathbf{I}_{\text {Corr. }} \boldsymbol{\mu A} / \mathbf{c m}^{2}$ & Corrosion rate (mpy) & $\begin{array}{l}\text { Inhibition efficiency } \\
\text { IE\% }\end{array}$ \\
\hline Blank & 66.43 & 3.280 & $1485 \times 10^{-3}$ & - \\
\hline Blank+ 0.005M Leucine & 48.84 & 1.420 & $643.1 \times 10^{-3}$ & 56.7 \\
\hline Blank+ 0.05M Leucine & 28.39 & 1.442 & $653.1 \times 10^{-3}$ & 56.0 \\
\hline Blank+ 0.1M Leucine & -35.42 & 2.180 & $990.8 \times 10^{-3}$ & 33.5 \\
\hline
\end{tabular}

Table 6. Corrosion parameters and inhibition efficiency for $316 \mathrm{~L}$ stainless steel in absence and presence of different concentrations of Valine

\begin{tabular}{|l|l|l|l|l||}
\hline $\begin{array}{l}\text { Conc } \\
\mathbf{M}\end{array}$ & $\mathbf{E}_{\text {Corr. }} \mathbf{~} \mathbf{V}$ & $\mathbf{I}_{\text {Corr. }} \boldsymbol{\mu A} / \mathbf{c m}^{2}$ & Corrosion rate (mpy) & $\begin{array}{l}\text { Inhibition efficiency } \\
\text { IE\% }\end{array}$ \\
\hline Blank & 66.43 & 3.280 & $1485 \times 10^{-3}$ & - \\
\hline Blank+ 0.005M Valine & 9.275 & 1.523 & $703.1 \times 10^{-3}$ & 53.5 \\
\hline Blank+ 0.05M Valine & 24.80 & 1.832 & $829.4 \times 10^{-3}$ & 44.14 \\
\hline $\begin{array}{l}\text { Blank + 0.1M } \\
\text { Valine }\end{array}$ & 180.0 & 2.024 & $916.4 \times 10^{-3}$ & 38.29 \\
\hline
\end{tabular}


Table 7. Corrosion parameters and inhibition efficiency for 316L stainless steel in absence and presence of different concentrations of Arginine

\begin{tabular}{|l|l|l|l||}
\hline $\begin{array}{l}\text { Conc } \\
\mathbf{M}\end{array}$ & $\begin{array}{l}\mathbf{E}_{\text {Corr. }} \\
\mathbf{m V}\end{array}$ & $\begin{array}{l}\mathbf{I}_{\text {Corr. }} \\
\boldsymbol{\mu A} / \mathbf{c m}^{2}\end{array}$ & Corrosion rate (mpy) \\
\hline Blank & 66.43 & 3.280 & $1485 \times 10^{-3}$ \\
\hline Blank + 0.005M Arginine & -28.56 & 4.323 & $1958 \times 10^{-3}$ \\
\hline Blank + 0.05M Arginine & -25.75 & 5.809 & $2631 \times 10^{-3}$ \\
\hline Blank + 0.1M Arginine & -44.99 & 7.882 & $3569 \times 10^{-3}$ \\
\hline
\end{tabular}
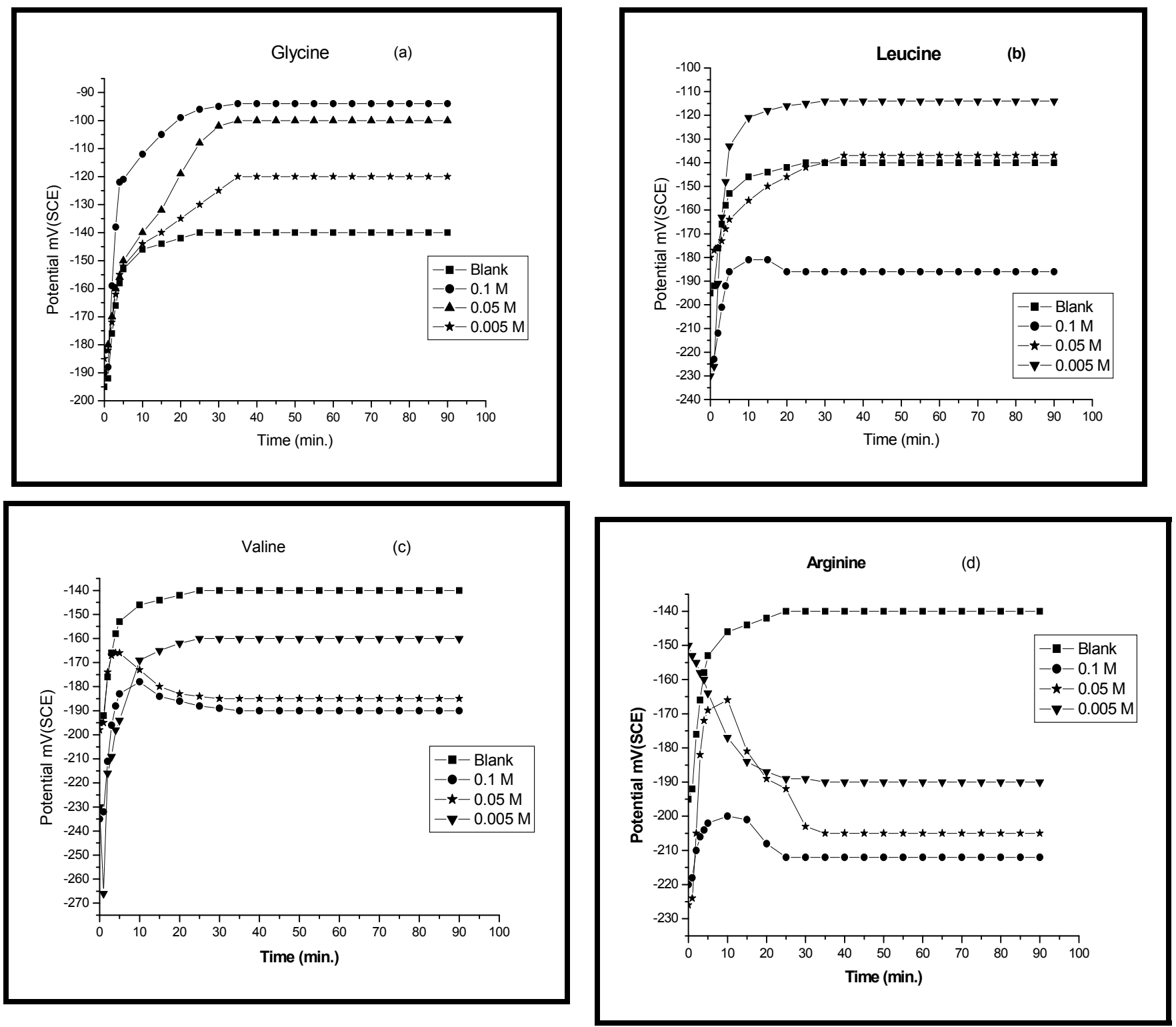

Figure 1. Variation of the open-circuit potentials of $316 \mathrm{~L}$ stainless steel with time in $1.0 \mathrm{M} \mathrm{H}_{2} \mathrm{SO}_{4}$ containing (a) Glycine, (b) Leucine, (c) Valine and (d) Arginine 


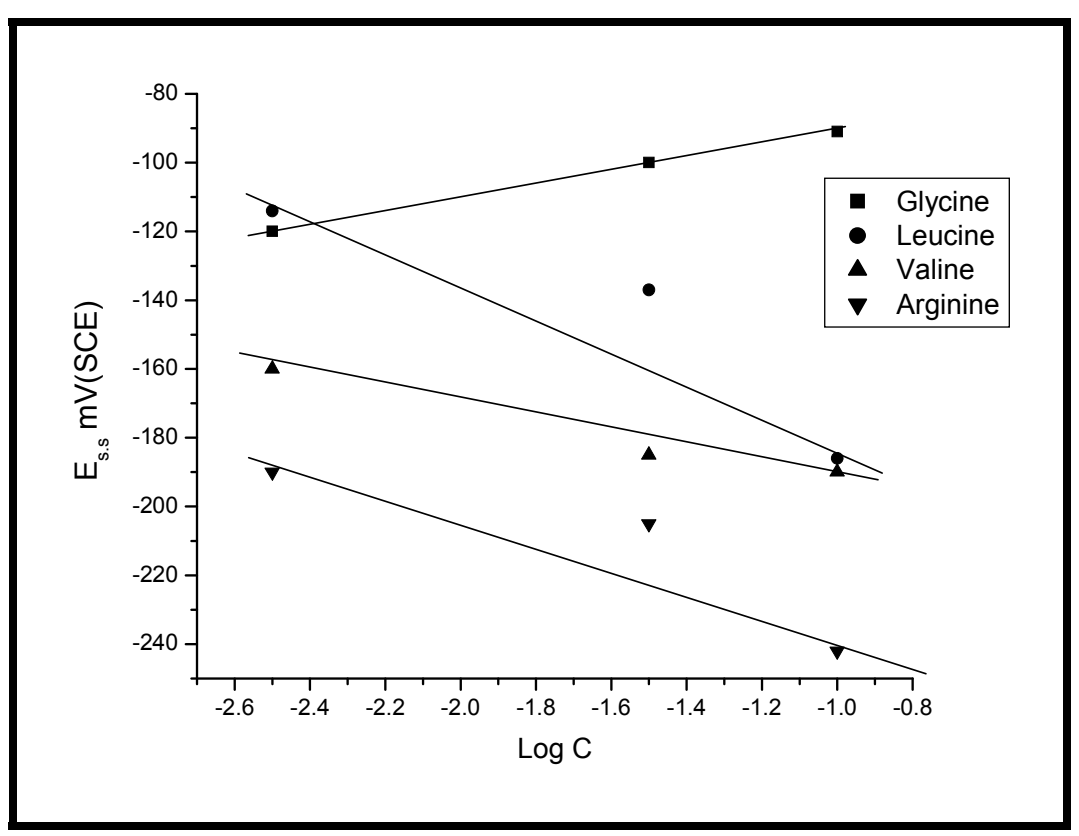

Figure 2. $\mathrm{E}_{\mathrm{s} . \mathrm{s}^{-}} \log$ Conc.curves of 316L stainless steel electrode in different amino acids solutions

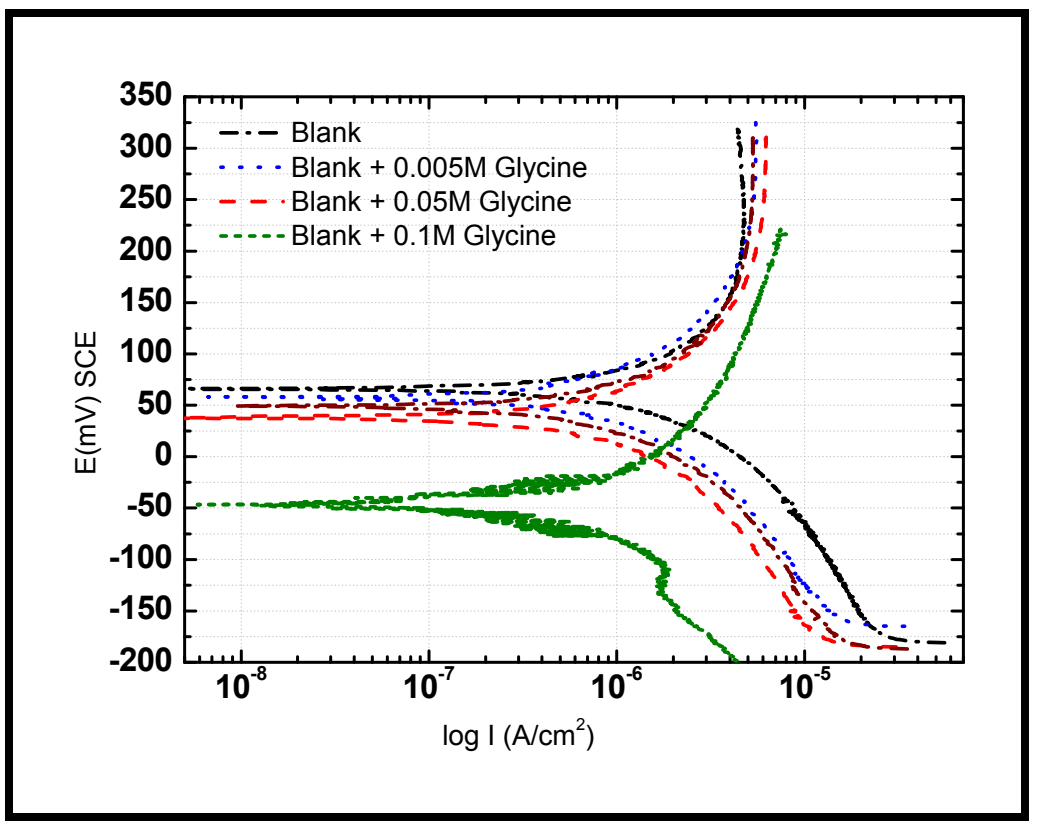

Figure 3. Polarization curves for the effect of different concentrations of Glycine on the potentiodynamic behaviour of $316 \mathrm{~L}$ stainless steel in $1.0 \mathrm{M} \mathrm{H}_{2} \mathrm{SO}_{4}$<smiles>[R]C(N)C(=O)O</smiles>

Protonated form

(Acidic solution) 


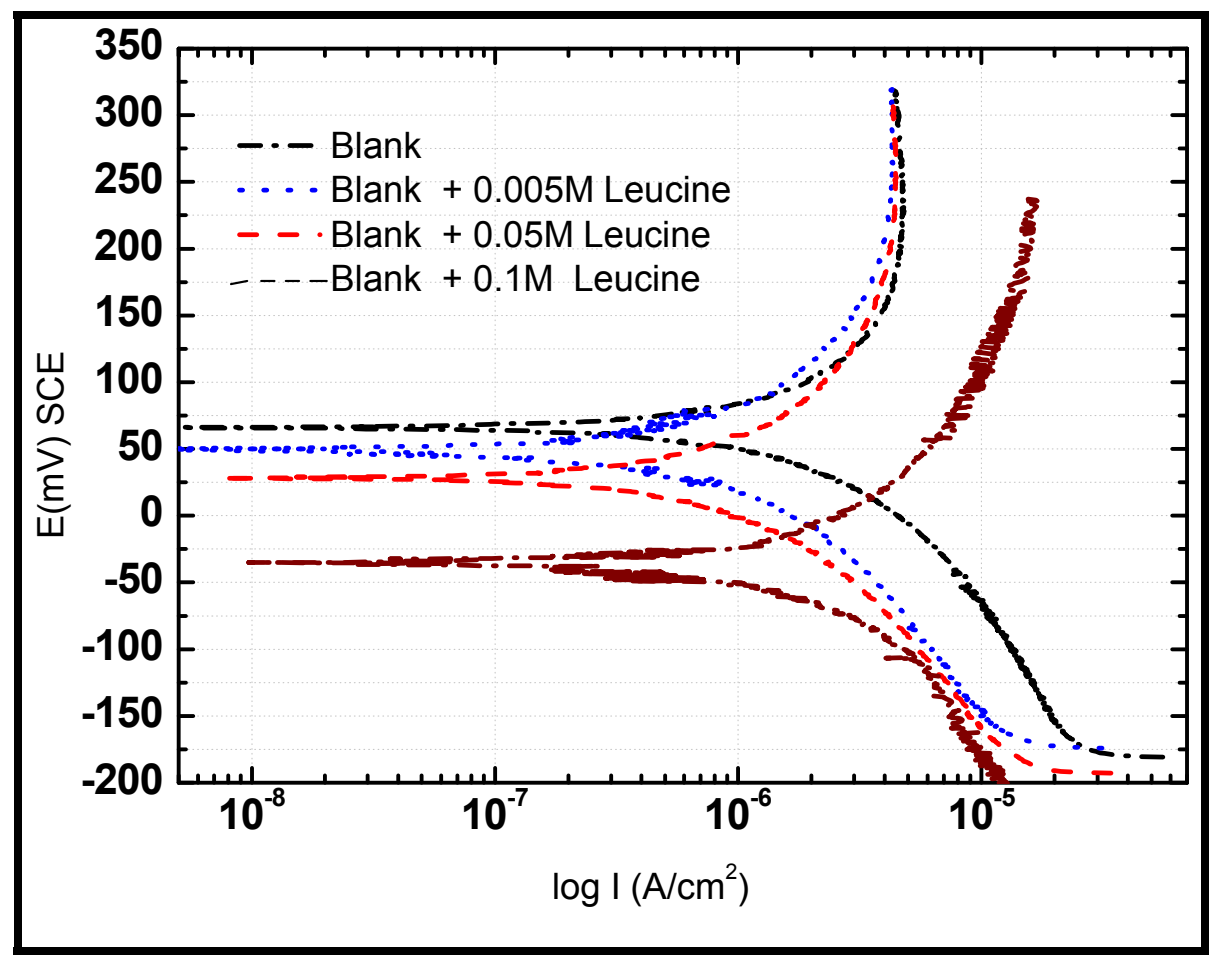

Figure 4. Polarization curves for the effect of different concentrations of Leucine on the potentiodynamic behaviour of $316 \mathrm{~L}$ stainless steel in $1.0 \mathrm{M} \mathrm{H}_{2} \mathrm{SO}_{4}$

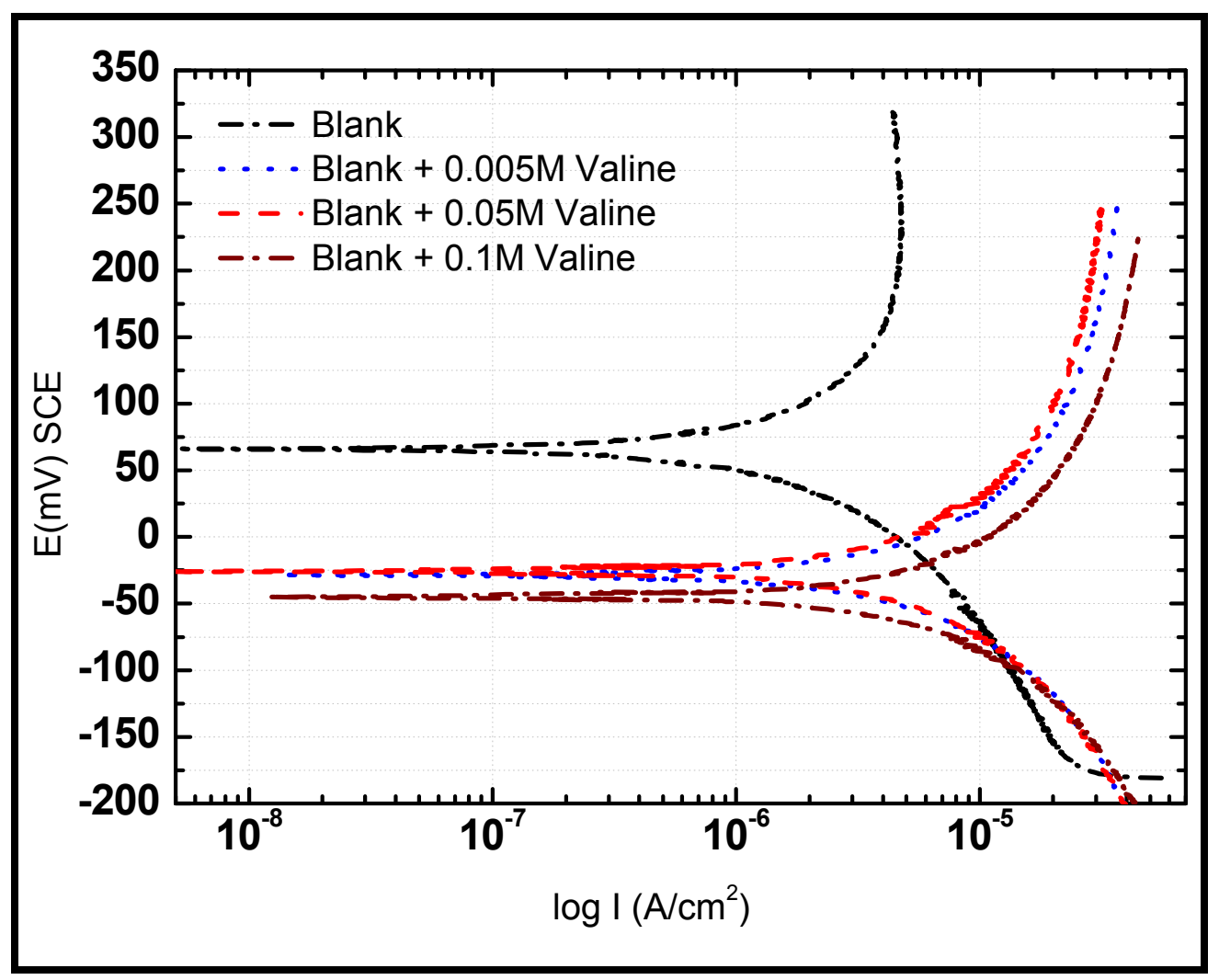

Figure 5. Polarization curves for the effect of different concentrations of Valine on the potentiodynamic behaviour of $316 \mathrm{~L}$ stainless steel in $1.0 \mathrm{M} \mathrm{H}_{2} \mathrm{SO}_{4}$ 


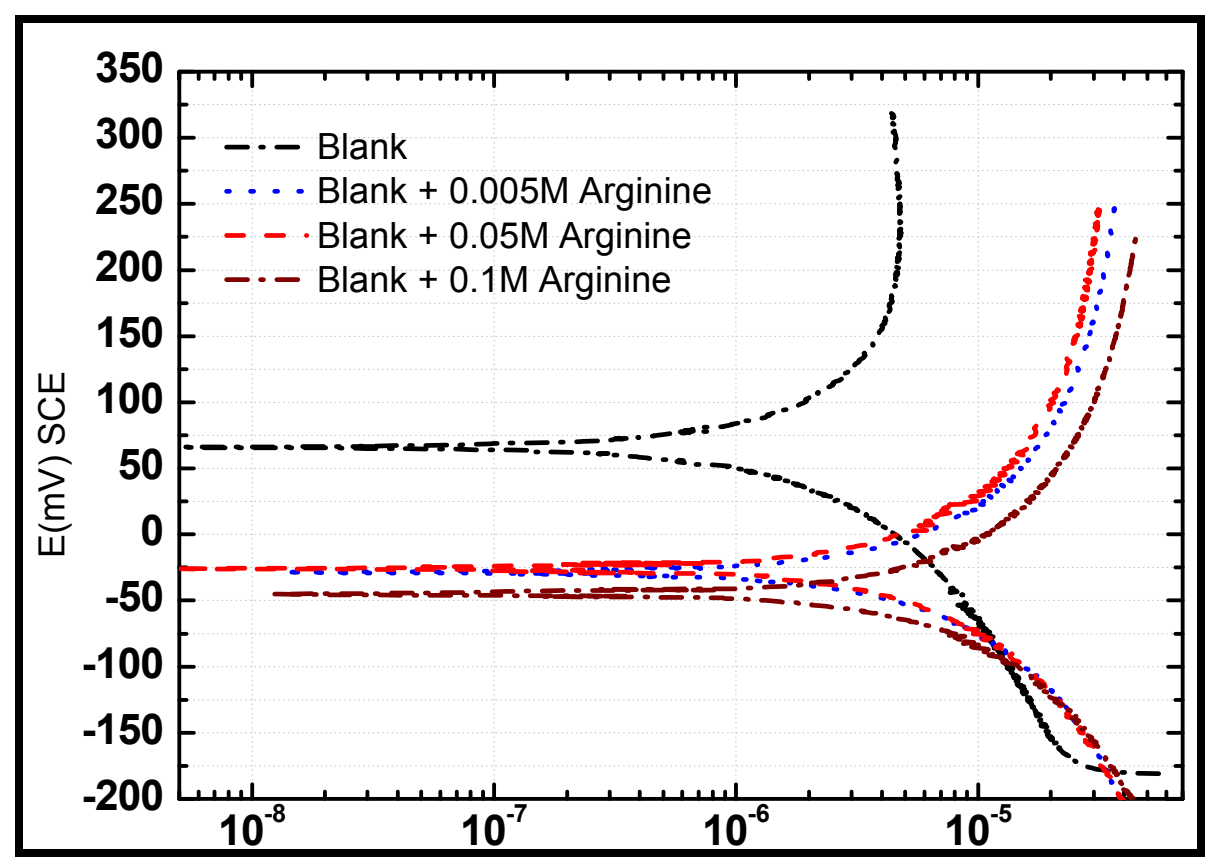

Figure 6. Polarization curves for the effect of different concentrations of Arginine on the potentiodynamic behaviour of $316 \mathrm{~L}$ stainless steel in $1.0 \mathrm{M} \mathrm{H}_{2} \mathrm{SO}_{4}$ 